\title{
A Direct DFT Trajectory Study of the Bis-superoxo $\operatorname{FAl}\left(\mathrm{O}_{2}\right)_{2}$ Ionization
}

\author{
Carlos J. Cobos \\ Instituto de Investigaciones Fisicoquímicas Teóricas y Aplicadas (INIFTA), Departamento de \\ Química, Facultad de Ciencias Exactas, Universidad Nacional de La Plata, CONICET, CICPBA, \\ Casilla de Correo 16, Sucursal 4, (1900) La Plata, Argentina \\ Reprint requests to Dr. C. J. C.; E-mail: cobos@ inifta.unlp.edu.ar \\ Z. Naturforsch. 63a, 49-52 (2008); received July 3, 2007
}

Direct density functional theory (DFT) classical trajectory calculations show that after bissuperoxo $\mathrm{FAl}\left(\mathrm{O}_{2}\right)_{2}$ ionization, one of the side-on dioxygen units undergoes a fast intramolecular rearrangement generating a stable radical cation which presents both a peroxo and a peroxyl group bound to the central $\mathrm{Al}$ atom, $\mathrm{FAl}\left(\mathrm{O}_{2}\right) \mathrm{OO}^{+}$. Molecular properties of this predicted novel species have been estimated at the B3PW91/6-311+G(3df) and G3B3 levels of theory.

Key words: $\mathrm{FAl}\left(\mathrm{O}_{2}\right)_{2} ; \mathrm{FAl}\left(\mathrm{O}_{2}\right) \mathrm{OO}^{+}$; Classical Trajectory Calculations; Density Functional Theory.

\section{Introduction}

The detection of bis-superoxo $\operatorname{FAl}\left(\mathrm{O}_{2}\right)_{2}$ has been recently reported [1]. This compound is formed during 254-nm stationary photolysis of AlF in the presence of $\mathrm{O}_{2}$ in a solid argon matrix at $13 \mathrm{~K}$. The molecular structure for the triplet electronic ground state and the assignment of the observed infrared bands have been estimated from density functional theory (DFT) calculations [1,2]. Peroxo group-containing compounds play a significant role in preparative chemistry [3] and in biological processes [4]. On the other hand, very little is known about the chemistry of bissuperoxo compounds $[1,2,4]$ and essentially nothing about their ionized species. This paper reports the results of a theoretical study of $\operatorname{FAl}\left(\mathrm{O}_{2}\right)_{2}$ ionization and presents estimated molecular properties for the radical cation $\mathrm{FAl}\left(\mathrm{O}_{2}\right) \mathrm{OO}^{+}$. For this, classical trajectories were computed directly on a potential energy surface which accounts for the twelve degrees of freedom of $\mathrm{FAl}\left(\mathrm{O}_{2}\right)_{2}$. Details of the employed method are given in [5-7]. The energy and the forces employed in each step were computed using the hybrid B3PW91 functional $[8,9]$ combined with the $6-311 \mathrm{G}(\mathrm{d})$ basis set. All molecular orbital calculations were carried out by using the Gaussian 03 program package [10].

\section{Classical Trajectory Calculations}

Following the vertical ionization process, a vibrationally excited radical cation in a doublet ground state with a structure identical to the neutral precursor and with an excess energy of $273.5 \mathrm{kcal} \mathrm{mol}^{-1}$ is initially formed. Thirty trajectories, starting with different initial molecular configurations at 10 and $300 \mathrm{~K}$, were calculated. A time step of $0.5 \mathrm{fs}$ was used for the numerical integration of Newton's equations of motion of the nuclei. Figure 1a illustrates a snapshot of the initial conformation of the radical cation and the time evolution of its bond distances for representative sample trajectories. As expected, by changing the temperature from 10 to $300 \mathrm{~K}$ the atomic motions exhibit larger amplitudes of vibration due to thermal excitation. The initial F-Al bond distance in the radical cation is $1.653 \AA$. After a fast decay it reaches a slightly smaller value of $1.62 \AA$. Concomitantly, the Al- $\mathrm{O}_{a}$ and $\mathrm{Al}-\mathrm{O}_{\mathrm{b}}$ bonds of one of the peroxo groups are shortened, and remain near to $1.87 \AA$ from 150 fs. Simultaneously, the bond connecting the $\mathrm{O}$ atoms, $\mathrm{O}_{a}$ and $\mathrm{O}_{\mathrm{b}}$, decreases from $1.356 \AA$, and later reaches a bond distance of $1.40 \AA$ at about 200 fs. The excited peroxo group exhibits a quite different dynamical behaviour. As Fig. 1a shows, the $\mathrm{Al}-\mathrm{O}_{\mathrm{c}}$ and $\mathrm{Al}-\mathrm{O}_{\mathrm{d}}$ bonds are equally elongated, reaching a value close to $2.3 \AA$ at 150 fs. Concomitantly, the bond linking the $\mathrm{O}$ atoms $\mathrm{O}_{\mathrm{c}}$ and $\mathrm{O}_{\mathrm{d}}$ decreases. Afterwards, the $\mathrm{Al}-\mathrm{O}_{\mathrm{c}}$ bond reaches a maximum elongation of about $2.4 \AA$ at $225 \mathrm{fs}$, and later restoring bonding forces reduce this distance to about $2.1 \AA$. The $\mathrm{Al}-\mathrm{O}_{\mathrm{d}}$ bond is broken close to $400 \mathrm{fs}$, at the corresponding final interatomic distance of $2.98 \AA$ (not shown in Fig. 1a). Therefore, as a result of $\operatorname{FAl}\left(\mathrm{O}_{2}\right)_{2}$ ionization, a side-on coordi- 

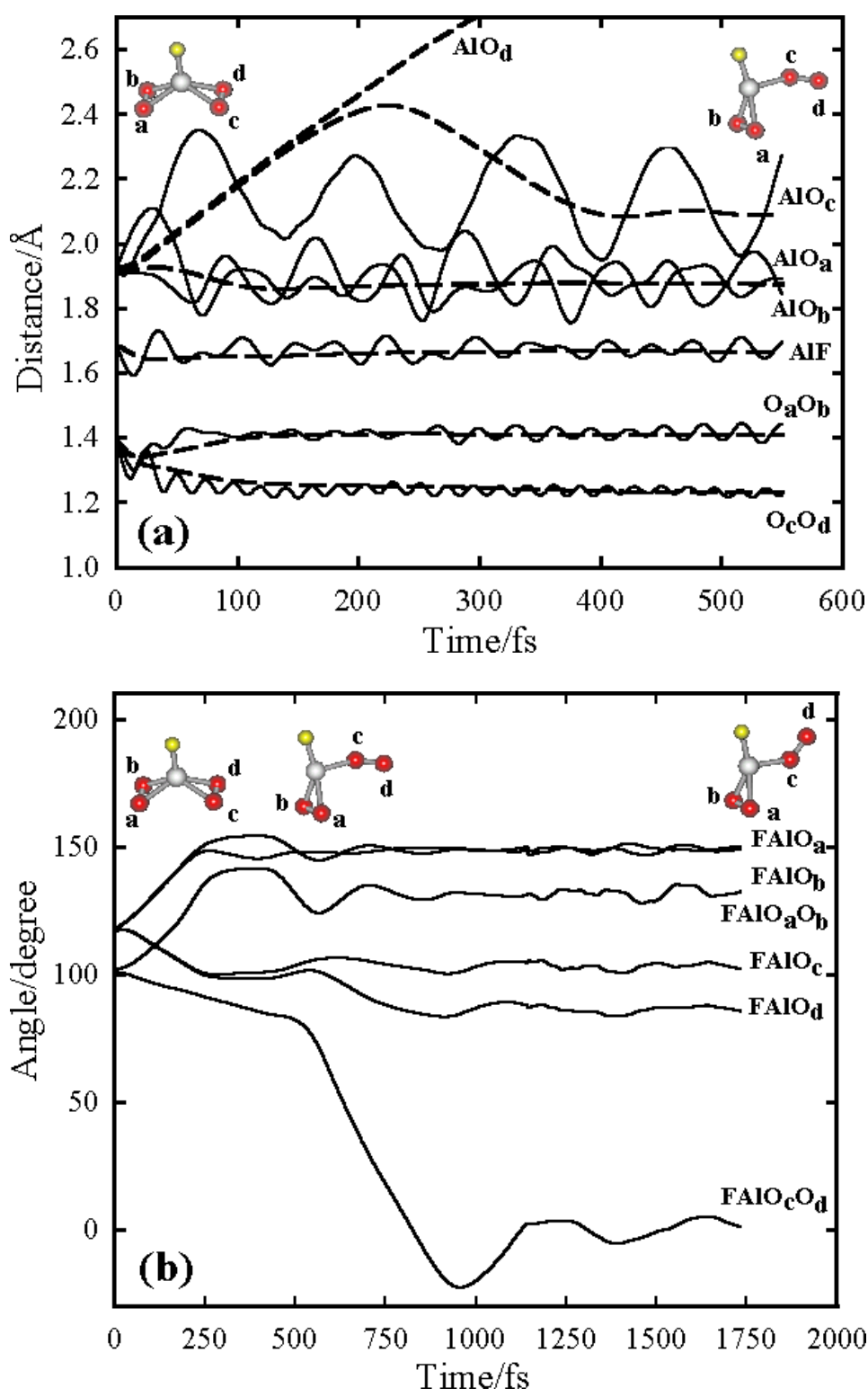

Fig. 1. Time evolution of the bond distances and angles following the $\operatorname{FAl}\left(\mathrm{O}_{2}\right)_{2}$ ionization. (a) B3PW91/6-311G(d) calculations at $10 \mathrm{~K}(---)$ and $300 \mathrm{~K}(-)$; snapshots of the radical cation configurations at 0 and 550 fs. (b) B3PW91/6-311G(d) calculations at $10 \mathrm{~K}$; snapshots at 0,550 and $1750 \mathrm{fs}$. nated dioxygen unit evolves into a terminal peroxyl moiety. A snapshot of the molecular structure at $550 \mathrm{fs}$ is shown in Figure 1a. At this stage, $39.2 \mathrm{kcal} \mathrm{mol}^{-1}$ of the initial excess energy have been employed in intramolecular rearrangement processes and to break one Al-O bond.

The evolution of the F-Al-O and F-Al-OO angles along a larger timescale are shown in Figure $1 \mathrm{~b}$. The F-Al- $\mathrm{O}_{\mathrm{a}}$ and $\mathrm{F}-\mathrm{Al}-\mathrm{O}_{\mathrm{b}}$ angles corresponding to the conserved peroxo group change from $117.1^{\circ}$ to about $148^{\circ}$. This fact is probably due to the decrease of the repulsive energy forces between the conserved and the disappearing peroxo groups along the process. Concurrently, the F-Al- $\mathrm{O}_{\mathrm{c}}$ and $\mathrm{F}-\mathrm{Al}-\mathrm{O}_{\mathrm{d}}$ angles are somewhat reduced. More pronounced changes occur in the F-Al- $\mathrm{O}_{\mathrm{c}} \mathrm{O}_{\mathrm{d}}$ torsional mode of the excited peroxyl group, which is almost decoupled from the other internal motions. In fact, after a slow linear decrease from $101.6^{\circ}$, a much stronger reduction of this angle leads asymptotically to a final value for F-Al-OO(b) of $0^{\circ}$. In summary, the simulations indicate that one of the side-on dioxygen units of the prompt formed un- 
stable radical cation undergoes a fast impulsive repulsion from the central $\mathrm{Al}$ atom and, subsequently, one of the Al-O bonds is broken. Afterwards, as Fig. 1b shows, a free torsional motion around the remaining $\mathrm{Al}-\mathrm{O}_{\mathrm{c}} \mathrm{O}_{\mathrm{d}}$ bond leads to the almost energetically and structurally relaxed species indicated by the snapshot recorded at $1750 \mathrm{fs}$.

\section{Molecular Properties of $\mathrm{FAl}\left(\mathrm{O}_{2}\right) \mathrm{OO}^{+}$}

The dynamical study was complemented with electronic structure calculations of the relevant species. The flow of the atomic charges from $\operatorname{FAl}\left(\mathrm{O}_{2}\right)_{2}$ to thermalized $\mathrm{FAl}\left(\mathrm{O}_{2}\right) \mathrm{OO}^{+}$was investigated using the theory of atoms in molecules (AIM) [11,12]. The computed charge distributions obtained at the B3PW91/6-311+G(3df) level of the theory can be expressed as $\mathrm{F}^{0.858-} \mathrm{Al}^{2.56+}\left(\mathrm{O}^{0.426-} \mathrm{O}^{0.426-}\right)_{2}$ and $\mathrm{F}^{0.819-} \mathrm{Al}^{2.56+}\left(\mathrm{O}^{0.396-} \mathrm{O}^{0.396-}\right) \mathrm{O}^{0.247-} \mathrm{O}^{0.298+}$. These results clearly indicate that the peroxo group that evolves into peroxyl undergoes more relevant changes. In addition, the cation charge is mainly located at the terminal $\mathrm{O}$ atom of this group.

The energetics were accurately determined by using the G3B3 ab initio model chemistry [13]. From the calculated total atomization energy of $483.8 \mathrm{kcal} \mathrm{mol}^{-1}$, an enthalpy of formation of $-152.6 \mathrm{kcal} \mathrm{mol}^{-1}$ was obtained for gaseous $\operatorname{FAl}\left(\mathrm{O}_{2}\right)_{2}$ at $1 \mathrm{~atm}$ and $298.15 \mathrm{~K}$. By adding to this value the computed enthalpy difference between the optimized neutral and ionic species of $240.8 \mathrm{kcal} \mathrm{mol}^{-1}$, a standard enthalpy of formation for $\mathrm{FAl}\left(\mathrm{O}_{2}\right) \mathrm{OO}^{+}$of $88.2 \mathrm{kcal} \mathrm{mol}^{-1}$ was predicted. In addition, calculations performed along the minimum energy path of the reaction $\mathrm{FAl}\left(\mathrm{O}_{2}\right) \mathrm{OO}^{+} \rightarrow \mathrm{FAl}\left(\mathrm{O}_{2}\right)^{++}+\mathrm{O}_{2}$ indicate that the reverse association reaction is a barrierless process being the change of enthalpy for the dissociation process of $22.0 \mathrm{kcal} \mathrm{mol}^{-1}$. However, mainly due to the abovementioned separation of charges in $\mathrm{FAl}\left(\mathrm{O}_{2}\right) \mathrm{OO}^{+}$, a larger value of $34.2 \mathrm{kcal} \mathrm{mol}^{-1}$ was found for the reaction $\mathrm{FAl}\left(\mathrm{O}_{2}\right)_{2} \rightarrow \mathrm{FAlO}_{2}+\mathrm{O}_{2}$. From these results, en-

[1] J. Bahlo, H.-J. Himmel, and H. Schnöckel, Angew. Chem. Int. Ed. Engl. 40, 4696 (2001).

[2] J. Bahlo, H.-J. Himmel, and H. Schnöckel, Inorg. Chem. 41, 4488 (2002).

[3] W. A. Herrmann, J. Organomet. Chem. 500, 149 (1995). thalpies of formation of -118.4 and $110.2 \mathrm{kcal} \mathrm{mol}^{-1}$ were, respectively, derived for singlet $\mathrm{FAl}\left(\mathrm{O}_{2}\right)$ and $\mathrm{FAl}\left(\mathrm{O}_{2}\right)^{++}$.

The knowledge of the IR and UV-Vis spectra of $\mathrm{FAl}\left(\mathrm{O}_{2}\right) \mathrm{OO}^{++}$may help in experimental characterization. These properties were also estimated with the functional B3PW91/6-311+G(3df). The derived harmonic vibrational frequencies and IR intensities (in units of $10^{3} \mathrm{~m} \mathrm{~mol}^{-1}$ in brackets) are the following: 1649 (37), 1160 (12), 1006 (137), 623 (50), 578 (0.6), 367 (81), 246 (39), 201 (70), 168 (38), 129 (1), $97(0.9)$ and $83 \mathrm{~cm}^{-1}(0.6)$. The more intense band at $1006 \mathrm{~cm}^{-1}$ is assigned to the combination of the F-Al stretching mode and the O-Al-O bending mode, and could be of importance in the $\mathrm{FAl}\left(\mathrm{O}_{2}\right) \mathrm{OO}^{+}$ identification. Finally, time-dependent DFT calculations [14] suggest that $\mathrm{FAl}\left(\mathrm{O}_{2}\right) \mathrm{OO}^{+}$exhibits a strong absorption band centred at $232 \mathrm{~nm}$ (oscillator strength of 0.0393) attributable to electronic transitions located mainly on the molecular orbitals of the peroxyl group. Additional weaker bands at 244 and $352 \mathrm{~nm}$ with oscillator strengths of 0.0082 and 0.0105 are also predicted.

\section{Conclusion}

In conclusion, the results of the present direct DFT classical trajectory study provide evidence for the formation of the novel radical cation $\operatorname{FAl}\left(\mathrm{O}_{2}\right) \mathrm{OO}^{+}$by ionization of $\operatorname{FAl}\left(\mathrm{O}_{2}\right)_{2}$. This constitutes the first example of a molecule with both peroxo and peroxyl groups linked to a central $\mathrm{Al}$ atom and, to our knowledge, linked to any other metal centre. The present results ask for experimental measurements which enable to detect and characterize the predicted radical cation.

\section{Acknowledgement}

This work was supported by the UNLP, the CONICET, the CICPBA, the ANPCyT and the Max Planck Institute for Biophysical Chemistry (Karl Friedrich Bonhoeffer Institute) through the "Partner Group for Chlorofluorocarbons in the Atmosphere".

[4] N. Kitajima and Y. Moro-oka, Chem. Rev. 94, 737 (1994).

[5] W.F. van Gunsteren and H. J.C. Berendsen, Angew. Chem. Int. Ed. Engl. 29, 992 (1990).

[6] E. Uggerud and T. Helgaker, J. Am. Chem. Soc. 114, 4265 (1992). 
[7] H. Tachikawa, J. Phys. Chem. A 106, 6915 (2002).

[8] A. D. Becke, Phys. Rev. A 38, 3098 (1988).

[9] J. P. Perdew, in: Electronic Structure of Solids '91 (Eds. P. Ziesche and H. Eschrig), Akademie Verlag, Berlin 1991, p. 11.

[10] M. J. Frisch, G. W. Trucks, H. B. Schlegel, G. E. Scuseria, M. A. Robb, J. R. Cheeseman, J. A. Montgomery, Jr., T. Vreven, K. N. Kudin, J.C. Burant, J. M. Millam, S. S. Iyengar, J. Tomasi, V. Barone, B. Mennucci, M. Cossi, G. Scalmani, N. Rega, G. A. Petersson, H. Nakatsuji, M. Hada, M. Ehara, K. Toyota, R. Fukuda, J. Hasegawa, M. Ishida, T. Nakajima, Y. Honda, O. Kitao, H. Nakai, M. Klene, X. Li, J.E. Knox, H. P. Hratchian, J. B. Cross, C. Adamo, J. Jaramillo, R. Gomperts, R. E. Stratmann, O. Yazyev, A. J. Austin, R. Cammi, C. Pomelli, J. W. Ochterski, P. Y. Ayala, K. Morokuma, G. A. Voth, P. Salvador, J. J. Dannenberg, V. G. Zakrzewski, S. Dapprich, A. D. Daniels, M.C. Strain, O. Farkas, D. K. Malick, A. D.
Rabuck, K. Raghavachari, J. B. Foresman, J. V. Ortiz, Q. Cui, A. G. Baboul, S. Clifford, J. Cioslowski, B. B. Stefanov, G. Liu, A. Liashenko, P. Piskorz, I. Komaromi, R. L. Martin, D. J. Fox, T. Keith, M. A. AlLaham, C. Y. Peng, A. Nanayakkara, M. Challacombe, P. M.W. Gill, B. Johnson, W. Chen, M.W. Wong, C. Gonzalez, and J.A. Pople, Gaussian 03, Revision C.02, Gaussian, Inc., Pittsburgh, PA 2004.

[11] R.F. W. Bader, Atoms in Molecules, in: Encyclopedia of Computational Chemistry, Vol. 1 (Eds. P. von R. Schleger et al.), John Wiley \& Sons, New York 1998, p. 64.

[12] B. B. Stefanov and J. R. Cioslowski, J. Comp. Chem. 16, 1394 (1995), and references therein.

[13] A. G. Baboul, L.A. Curtis, P.C. Redfern, and K. Raghavachari, J. Chem. Phys. 110, 7650 (1999).

[14] M. E. Casida, C. Jamorski, K. C. Casida, and D. R. Salahub, J. Chem. Phys. 108, 4439 (1998). 